\title{
"Califórnia decreta emergência após vazamento de óleo": o uso do presente para noticiar eventos passados
}

\section{Caroline Soares ${ }^{1}$ \\ Lilian Ferrari ${ }^{2}$}

Resumo: Este artigo examina escolhas temporais em manchetes e subtítulos de jornais online em português, sob a perspectiva da Gramática Cognitiva. A análise tem o objetivo de investigar os mecanismos cognitivos associados ao uso do Presente do Indicativo para referência a eventos passados, contrastando-o com usos do Passado no mesmo contexto. A investigação parte da noção de imediaticidade epistêmica, referente ao presente simples em inglês (LANGACKER, 2001, 2009), expandindo-a para acomodar atos de fala. Os resultados indicam que o uso do Presente do Indicativo predomina tanto em manchetes quanto em subtítulos, embora a combinação mais frequente seja MANCHETE (Presente) - SUBTÍTULO (Passado).

Palavras-chave: Manchete jornalística. Subtítulo. Presente do indicativo. Estrutura conceptual.

\begin{abstract}
This paper examines temporal choice in headlines and subtitles of Brazilian online newspapers. The analysis is based on Cognitive Grammar, and aims at investigating the cognitive underpinnings for using the Present of the Indicative to refer to past events, contrasting it with uses of past tense. The investigation draws on the notion of epistemic imediaticity, associated to the present simple in English (LANGACKER, 2001, 2009), and expands it to accommodate speech act uses. The results show that the Present of the Indicative predominates in both headlines and subtitles, although the most frequent combination is HEADLINE (Present) - SUBTITLE (Past).

Keywords: Journalistic headline. Subtitle. Present tense. Conceptual structure.

1 Doutoranda em Linguística pela Universidade Federal do Rio de Janeiro. Possui Mestrado em Estudos da Linguagem (2013/1), Especialização em Leitura e Produção de textos (2005) e em Língua Portuguesa (2007) pela Universidade Federal Fluminense.

2 Professora Titular do Departamento de Linguística e Filologia, e membro permanente do Programa de Pós-Graduação em Linguística da Universidade Federal do Rio de Janeiro. Possui Mestrado em Linguística pela Universidade Federal do Rio de Janeiro (1985), Doutorado em Linguística pela University of Southern California, Los Angeles/ Universidade Federal do Rio de Janeiro (1994), e Pós-doutorado na University of California, Berkeley (2006).
\end{abstract}

Este artigo está licenciado sob forma de uma licença Creative Commons Atribuição 4.0 Internacional,

que permite uso irrestrito, distribuição e reprodução em qualquer meio, desde que a publicação

original seja corretamente citada. https://creativecommons.org/licenses/by/4.0/deed.pt BR. 
Résumé: L'article analyse les choix des temps verbaux des titres et sous-titres des journaux brésiliens en ligne, à partir de la Grammaire Cognitive. L'étude se concentre sur les mécanisme cognitifs associés à l'utilisation du Présent de l'Indicatif, pour se référer aux événements du passé, contrastant avec les usages des temps verbaux du Passé. L'analyse est basée sur la notion d'immédiateté épistémique associée au présent simple en anglais (LANGACKER, 2001, 2009), l'élargissant aux actes du discours. Les résultats montrent que l'utilisation du Présent de l'Indicatif prédomine dans les titres et sous-titres, bien que la combinaison la plus fréquente soit TITRE (Présent) - SOUS-TITRE (Passé).

Mots-clès: Titre journalistique. Sous-titre. Présent de l'indicatif. Structure conceptuelle.

\section{Introdução}

Este trabalho tem como proposta analisar, sob a perspectiva teórica da Linguística Cognitiva e, mais especificamente, sob o viés da Gramática Cognitiva, os aspectos cognitivos e pragmáticos de escolhas temporais em manchetes e subtítulos de jornais online (O Globo, Jornal do Brasil, Estadão e Folha de São Paulo).

A investigação do gênero jornalístico provém de uma vasta tradição de estudos, com raízes na retórica, na literatura e na filosofia (BAKTHIN, [1979]; 2003), e de desenvolvimentos subsequentes no âmbito da Linguística. No que se refere ao Português Brasileiro, destacam-se as propostas da Linguística Funcional, com trabalhos sobre a caracterização funcional dos gêneros textuais (DECAT, 2008) e, mais especificamente, sobre manchetes jornalísticas (SOARES, 2013), e a contribuição pioneira de Marcuschi (1999, 2000, 2008), no âmbito da Linguística Textual, destacando as inter-relações entre língua, cognição e sociedade. Para o linguista, esses três elementos contribuem para a produção de sentido no processo de textualização que, por sua vez, 
deve ser analisado de forma integrada ao processo de compreensão, considerado como atividade conjunta de produção de sentido.

$\mathrm{Na}$ obra de Marcuschi, duas premissas são especialmente relevantes para a abordagem cognitivista que orienta o presente trabalho: a proposta de que a compreensão humana é contextualmente configurada, e a concepção do sentido como resultado de atividades cognitivas mediadas pela experiência organizada socialmente em regime de coprodução. Em especial, ao situar a cognição humana como contextualmente configurada, e não como uma atividade subjetiva pautada apenas na aptidão mental ou na simples designação do mundo extra-mental, Marcuschi (1999) dialoga diretamente com a proposta cognitivista de Fauconnier \& Sweetser (1996), e prenuncia a noção de mente corporificada, que constitui um dos eixos norteadores da Linguística Cognitiva (LAKOFF; JOHNSON, 1999).

$\mathrm{Na}$ esteira desses estudos, e aprofundando seu escopo de atuação, o presente trabalho investiga as estruturas cognitivas associadas às manchetes e subtítulos jornalísticos. Assim, este artigo adota o referencial teórico da Linguística Cognitiva e, particularmente, os fundamentos da Gramática Cognitiva (LANGACKER, 1987, 1991, 2009), delimitando como objeto de estudo as escolhas verbais temporais/aspectuais para indicação de eventos ocorridos no PASSADO. Mais especificamente, enfocamos o uso do Presente do Indicativo, contrastando-o com usos de tempos do Pretérito (Pretérito Perfeito, Pretérito Imperfeito, Futuro do Pretérito), tendo em vista que essas duas categorias verbais correspondem às principais escolhas observadas no corpus. 
Na presente pesquisa, pretendemos demonstrar que as escolhas temporais nas manchetes e subtítulos de jornais online refletem processos cognitivos associados a aspectos pragmáticos e estratégias de focalização que visam atrair a atenção do leitor para a notícia.

A proposta a ser desenvolvida é a de que os conceitos da Gramática Cognitiva, aplicados ao estudo do tempo verbal, podem explicar aspectos relevantes da relação entre linguagem e cognição no contexto do jornalismo online, uma vez que as práticas discursivas constituem um ambiente de negociação intersubjetiva, do qual fazem parte os processamentos de conceptualização e de interação, fatores importantes para uma análise aprofundada do sentido investigado.

Argumentamos que as discussões sobre a semântica do Tempo Presente em inglês, de acordo com a proposta de Langacker (2001, 2009) podem lançar luz sobre a utilização desse tempo verbal em manchetes e subtítulos de jornais online em português. Em especial, a análise propõe uma extensão do modelo langackeriano, para explicar o fenômeno sob investigação. Por fim, enfocamos as inter-relações temporais entre manchetes e subtítulos.

O texto está organizado da seguinte forma: primeiramente, apresentaremos os pressupostos teóricos da Linguística Cognitiva e da Gramática Cognitiva. Em seguida, faremos uma breve revisão da proposta de Langacker sobre o Tempo Presente em inglês; nas seções seguintes, serão explicitadas a metodologia, a análise, e a discussão sobre os resultados da pesquisa. 


\section{Linguística cognitiva e gramática cognitiva}

Em linhas gerais, a Linguística Cognitiva defende que a relação entre linguagem e mundo é mediada pela cognição. Dentro dessa perspectiva, o significado deixa de ser um reflexo direto do nosso contato com o mundo, sendo concebido como uma construção mental que organiza nossas experiências. A perspectiva adotada é baseada no uso e tem como hipótese a ideia de que o contexto orienta a construção do significado, ou seja, o sentido convencional representa uma idealização, uma afirmação do seu significado prototípico com base nas interpretações pragmáticas.

Diferente das abordagens formais, a Linguística Cognitiva enfatiza a experiência humana e a centralidade do corpo humano; a cognição e a realidade são concebidas a partir de uma ancoragem corporal (LAKOFF; JOHNSON, 1999). De acordo com essa concepção, não há uma realidade objetivamente dada e o acesso a partes da realidade física é limitado pela natureza de nossa estrutura corporal (FERRARI, 2011).

Composta por vertentes inter-relacionadas, a Linguística Cognitiva tem a Gramática Cognitiva (LANGACKER, 1987, 1991) como um de seus carros-chefes. O modelo propõe, em linhas gerais, que as unidades linguísticas são estruturas simbólicas abstraídas de eventos de uso, que articulam estruturas fonológicas e conceptuais.

Para compreender como funciona a conceptualização, o autor destaca duas dimensões: o escopo e a proeminência. O primeiro é definido como a matriz de conteúdo conceptual que uma expressão 
evoca como base para seu significado, sendo o escopo máximo o conjunto completo desse conteúdo, e o escopo imediato a matriz específica de conteúdo em um nível particular de organização, também denominado como onstage ou locus geral de atenção. Outro conceito importante é o perfilamento, um tipo de proeminência, considerado o foco específico de atenção dentro do escopo imediato. Por exemplo, as expressões íris e pupila evocam a mesma base conceptual como escopo imediato - a configuração de um olho -, mas impõem perfilamentos diferentes a essa base.

Outra noção importante na Gramática Cognitiva é a de Viewing Arragement (Arranjo de Visualização), que constitui uma metáfora visual recrutada para tratar do modo pelo qual uma conceptualização é estabelecida. Langacker (2009) aponta dois modelos principais: Default Viewing Arrangement (Arranjo de Visualização Padrão) e Special Viewing Arrangement (Arranjo de Visualização Especial). No primeiro, os interlocutores estão juntos em um local fixo, a partir do qual observam e descrevem diretamente eventos do mundo (ex. A luz está acesa). De acordo com esse arranjo, uma sentença como 'Ele corta grama' não seria gramatical, justamente porque a observação direta do evento transcenderia a duração imposta pelo uso do presente. Para resgatar a gramaticalidade da sentença, entretanto, é possível recorrer ao segundo tipo de arranjo, no qual se estabelece um nível intermediário entre a expressão e o evento real; trata-se de um nível virtual que permite conceptualizar, no presente, um evento real que transcende o evento de fala. No caso da sentença mencionada 
anteriormente, o nível virtual se refere à conceptualização de um evento como um processo habitual ('Ele corta a grama (todos os dias)').

A noção de Viewing Arragement fundamenta a discussão de Langacker sobre o Tempo Presente em inglês, e estabelece interseções com o nosso objeto de estudo. Sendo assim, o conceito de arranjo de visualização será detalhado a seguir.

\section{A proposta da gramática cognitiva para o present tense em inglês}

A caracterização dos verbos constitui tema classicamente abordado no âmbito dos estudos da linguagem. Em especial, questões relacionadas a tempo, aspecto e modo verbal são discutidas a partir de uma vasta literatura, envolvendo múltiplas perspectivas teóricas. No caso do Presente do Indicativo, e estruturas correlatas em outras línguas, um ponto de convergência de interesses tem a ver com a aparente incongruência de usos que podem incluir situações não concomitantes ao evento de fala.

Com referência ao português, as abordagens tradicionais ilustram a multiplicidade semântica do Presente do Indicativo, que pode indicar presente momentâneo, habitual, durativo, histórico e com valor de futuro (CUNHA; CINTRA, 2001; SAID ALI, 1964). Em razão de seu objetivo normativo, entretanto, a preocupação das gramáticas tradicionais reside na prescrição de usos do presente a partir de exemplos que não discutem a língua em uso. Já as abordagens descritivas, partem da diversidade de significados apontada nas 
gramáticas tradicionais, para ressaltar que a vinculação entre tempo formal e tempo semântico é complexa, reivindicando, ainda, a necessidade de distinção entre tempo semântico e aspecto (PERINI, 2009; CASTILHO, 2010). No que se refere ao Presente do Indicativo, Castilho (2010) apresenta proposta baseada no uso, adotando uma subdivisão bastante detalhada: (i) Presente real, que coincide com o momento da fala e é subdividido em Presente estreito, ou perfectivo, que expressa ações pontuais; Presente largo, ou imperfectivo, utilizado nas situações de maior duração; e o Presente de hábito, ou iterativo, relacionado com ações que se repetem; (ii) Presente Metafórico dos usos fictícios, em que há trocas do presente pelo passado, pelo futuro do presente, pelo futuro do pretérito, pelo futuro do subjuntivo/indicativo e pelo imperfeito do subjuntivo; (iii) Presente atemporal, o presente dos ditados, das verdades eternas, de predisposição e dos marcadores discursivos.

Embora as gramáticas descritivas questionem conceitos normativos arbitrários e tragam uma visão mais pragmática da linguagem, ainda não consideram os aspectos cognitivos inerentes à relação entre os sujeitos envolvidos no ato comunicativo. Sendo assim, para o tratamento dos aspectos cognitivos envolvidos no uso do Presente, recorremos aos fundamentos da Gramática Cognitiva e à proposta específica de Langacker (2001) para o Present tense em inglês. Embora essa proposta não trate do uso do presente em manchetes jornalísticas, observamos que a análise desenvolvida pelo autor pode lançar luz sobre nosso objeto de estudo. 
O ponto principal é que, no artigo The English Present Tense (2001), Langacker discute o problema da conceituação do tempo Presente simples em inglês como indicativo de coincidência com o tempo de fala, e as ocorrências do seu uso em eventos que estão no passado ou no futuro, ou para expressar situações atemporais. A questão abordada é que o uso do presente para indicar exclusivamente eventos que ocorrem no momento da fala é, frequentemente, considerado pela maioria dos linguistas como impraticável; reconhecese que a escolha nestes casos é o uso do Presente progressivo, como em I am writing this paper right now em oposição a *I write this paper right now.

Langacker (2001) argumenta, entretanto, que o presente pode ser caracterizado como coincidente com o tempo da fala, desde que o significado seja equiparado à conceptualização. Tendo em vista que, nos termos da Gramática Cognitiva, toda expressão linguística sinaliza uma perspectiva em relação a uma cena, o autor reivindica que é possível caracterizar o Presente simples como uma maneira de interpretar o conteúdo conceptual.

Em capítulo posterior, The English present: Temporal coincidence vs. epistemic immediacy, Langacker (2009) aborda a questão da coincidência temporal versus a imediaticidade epistêmica nos usos do presente em inglês e reafirma que o Presente simples, ao contrário do que pensam diversos linguistas, pode ser analisado como marca do tempo Presente, apesar de sua caracterização "ingênua" indicando coincidência do evento descrito com o momento da fala não se sustentar. 
O autor propõe uma importante distinção conceitual básica das categorias de substantivo e verbo que são fundamentais para a compreensão da relação entre objetos e substâncias, e processos perfectivos e imperfectivos. Os substantivos se opõem gramaticalmente entre contável versus massivo, e a oposição análoga entre os verbos se manifesta nos processos perfectivos e imperfectivos. Os substantivos contáveis são considerados objetos físicos e os substantivos massivos, substâncias físicas; seu domínio de instanciação é o espaço. O domínio de instanciação dos verbos é o tempo.

Langacker estabelece um paralelismo interessante entre objetos e processos perfectivos, e substâncias e processos imperfectivos. Com relação ao primeiro caso (processos perfectivos), são consideradas as seguintes propriedades: limitado no escopo imediato de seu domínio de instanciação; não internamente homogêneo (objetos têm partes distintas constituídas de substâncias diferentes); não contrátil (uma subparte arbitrária não é, em si mesma, uma instância do mesmo tipo); replicável (duas instâncias em conjunto resultam em múltiplas instâncias). No segundo caso, as propriedades são conceitualmente opostas: substâncias e processos imperfectivos são considerados não limitados no escopo imediato. Por isso, são caracterizados em termos qualitativos, e não pela forma ou observação de um limite espacial; são internamente homogêneos (as mesmas propriedades qualitativas se mantêm ao longo da sua extensão espacial); são contráteis (qualquer porção de uma substância é em si uma instância do mesmo tipo); e não replicáveis (a combinação de duas instâncias resulta em um único caso maior). 
No caso dos nomes, o domínio em questão é o espaço, um substantivo contável perfila objetos limitados dentro do escopo espacial imediato, enquanto o substantivo massivo perfila substâncias não especificamente limitadas. Neste caso, qualquer subparte desse elemento é em si um exemplo válido da categoria, já que os nomes massivos são definidos como internamente homogêneos. Isso difere das características de nomes contáveis que se referem a um todo delimitado; portanto, uma parte limitada arbitrária de uma instância não constitui um exemplo da categoria.

No caso dos verbos, o que está sendo perfilado é o processo, um evento que ocorre sequencialmente e evolui. Portanto, o domínio relevante aqui é o tempo. O processo perfilado, construído como limitado no escopo imediato temporal, será expresso por um verbo perfectivo (por exemplo: cair, pular, jogar, quebrar, etc.); já eventos em que não é possível delimitar o processo, o verbo será imperfectivo, o que envolve uma amostragem de uma situação contínua que persiste ao longo do tempo (por exemplo: ser, ter, saber, acreditar, etc.). Análogos aos nomes massivos, os verbos imperfectivos são caracterizados como ilimitados e internamente homogêneos.

Já os verbos perfectivos apresentam propriedades dos nomes contáveis, uma vez que são interpretados como um todo delimitado. Neste caso, como o seu domínio de instanciação é o tempo, o que interessa é a sua extensão temporal, a relação perfilada que se estabelece a cada instante (fatias de tempo), que pode consistir em uma mudança através do tempo ou em uma continuação de uma situação estável. As imagens a seguir representam essas relações espaciais de 
objetos e substâncias, e temporais de processos perfectivos e imperfectivos.

Figura 1 - Relações espaciais de objetos e substâncias e temporais.

(a) Object

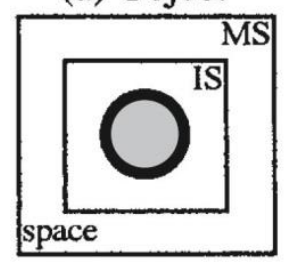

(b) Substance

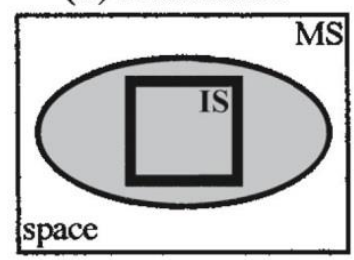

(c) Perfective Process

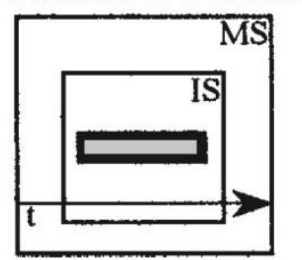

(d) Imperfective Process

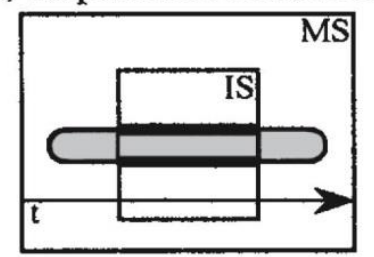

Fonte: Langacker (2009).

Na Figura 1, são apresentados diagramas que perfilam regiões específicas em relação aos escopos imediato (IS) e máximo (MS) da predicação. A figura (a) configura o objeto, cujas fronteiras e formas são inerentes à concepção de uma instância; por isso, elas se enquadram no escopo imediato. O sombreamento representa a substância material que constitui o objeto. A figura (b) evidencia que a delimitação não faz parte da caracterização de uma substância, escapando ao escopo imediato. Como ela é caracterizada em termos qualitativos, o importante é perceber que, partindo de uma grande extensão da substância, podemos direcionar nossa atenção para apenas uma de suas subpartes, que é considerada o alcance imediato de sua concepção. Quanto à figura (c), o processo perfectivo corresponde a uma caixa alongada com cantos quadrados, representando a sua relação de delimitação no tempo dentro do escopo imediato neste domínio; enquanto a figura (d) com cantos arredondados caracteriza a extensão temporal indefinida, indicando que a mesma relação se mantém ao longo do tempo. 
A definição de Langacker para o tempo Presente em inglês especifica que uma instância do processo perfilado ocorre e coincide precisamente com o momento da fala. Com relação às duas classes básicas de verbos - perfectivos (ativos) e imperfectivos (estáticos), o autor esclarece que o tempo Passado em inglês é compatível com essas duas classes semânticas, em razão desse último tempo não especificar o tamanho do escopo imediato que é imposto para a visão focalizada. Com relação ao Presente, o autor aponta que os imperfectivos podem ocorrer no presente, uma vez que o escopo imediato delimita apenas uma parte do processo global, e o perfilamento é limitado a esse segmento; mas a compatibilização do perfectivo com o tempo Presente é bastante problemática.

Em linhas gerais, o presente e o passado são elementos dêiticos que identificam o intervalo de tempo relativo ao evento de fala. Langacker apresenta três diagramas que representam as relações de passado, presente e o performativo com o evento de fala:

Figura 2 - Relações de passado, presente e o performativo.

(a) Past

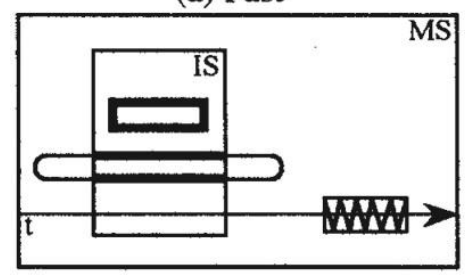

(b) Present

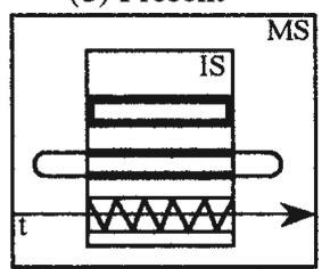

(c) Performative

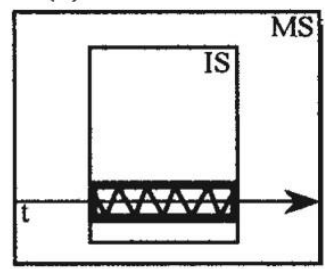

Fonte: Langacker (2009).

O evento de fala é representado por uma caixa com linhas onduladas. No caso do passado, o escopo imediato é anterior ao momento da fala, como podemos perceber na primeira figura. No caso dos performativos, o processo perfilado e o evento de fala são idênticos 
e, portanto, apresentam a mesma duração (Fig. 2(c)). Já no tempo presente, o escopo temporal imediato coincide com o evento de fala, gerando uma aparente incongruência no caso dos perfectivos. Por exemplo, a ocorrência de todas as etapas do evento 'jogar' (perfectivo) ultrapassa os limites do evento de fala.

De acordo com Langacker, esse é o motivo pelo qual a grande questão debatida por muitos linguistas é o tempo presente perfectivo. Entretanto, o autor apresenta uma proposta capaz de solucionar a aparente incongruência, defendendo que não há nada de estranho nessa configuração, que pode ser considerada conceptualmente coerente. Inicialmente, o autor reconhece que sentenças como *Sarah \{aprende um poema/faz uma ligação/planta seu jardim\} não ocorrem em situações normais, em razão do problema de duração do evento (geralmente é mais extensa do que o tempo de duração de um evento de fala), ou seja, a maioria dos eventos limitados não tem a mesma extensão de tempo necessária para proferir uma sentença.

Entretanto, a questão levantada pelo autor é a de que esses problemas surgem em virtude de um arranjo de visualização padrão, em que o falante e o ouvinte relatam as ocorrências reais a partir de um local fixo; uma configuração considerada básica e reducionista para lidar com as circunstâncias particulares que adotam o presente perfectivo. Nesse tipo de arranjo padrão, surgem problemas de duração e epistêmicos.

Para tratar do assunto, Langacker aborda os casos em que há um desvio desse sistema de visualização básico, como por exemplo, o relato play-by-play dos apresentadores esportivos, baseado em scripts, ou 
arranjos de visualização fictícia, nos quais se incluem o presente histórico, que relata fatos passados no presente, ou ainda o presente habitual, que indica fatos iterativos.

A proposta de Langacker (2009) para os casos de play-by-play e arranjos de visualização fictícia é a de que essas situações envolvem um esquema de visualização especial mais elaborado do que o padrão, que não se refere apenas à observação e descrição de ocorrências reais. $\mathrm{O}$ arranjo de visualização especial proposto para esses casos que desviam do padrão envolve a diferença entre um evento representado (real) e um evento de representação (virtual). Nesse esquema, esse último é descrito linguisticamente, mas toda a configuração que inclui o evento de representação e sua relação com o real faz parte do significado de uma expressão, como podemos observar na figura abaixo:

Figura 3 - a) Arranjo de visualização padrão; (b) Arranjo de visualização especial.

(a) Default Viewing Arrangement

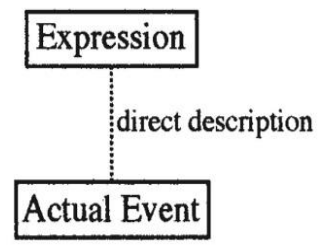

(b) Special Viewing Arrangement

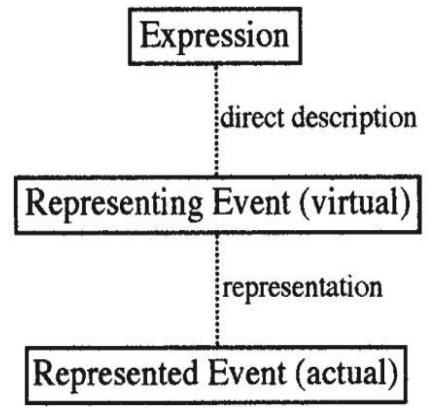

Fonte: Langacker (2009).

A Figura 3(a) indica arranjo de visualização padrão (default). Nesse arranjo, os interlocutores estão juntos em um local fixo, a partir do qual observam e descrevem eventos do mundo (por exemplo: Ivo viu o avião, A luz está acesa). A Figura 3(b), por sua vez, descreve o arranjo de visualização especial, em que não é a ocorrência real dos 
fatos que está sendo codificada linguisticamente, mas a ocorrência virtual.

A função semântica do tempo Presente está a serviço, nesse caso, de uma imediaticidade epistêmica, que não está associada à localização cronológica dos eventos reais, mas à certeza de sua ocorrência em termos de conceptualização da cena pelo falante.

A questão do Tempo Presente para indicar a imediaticidade epistêmica do processo perfilado, em oposição à definição da coincidência temporal entre o evento e o momento da fala, é discutida por Langacker (2009) através de questionamentos sobre essa imediaticidade ou certeza de ocorrência dos eventos. O relato de coincidência temporal considera a necessidade da ocorrência real dos fatos para que o evento perfilado coincida temporariamente com o evento de fala. No caso da ocorrência virtual, um evento "ocorre" com base na apreensão do falante sobre o conteúdo de uma cláusula finita, o que vai depender da natureza e proveniência do acontecimento. Por exemplo, um evento lembrado consiste em uma simulação mental realizada no presente, uma reativação parcial da experiência original.

Langacker argumenta, ainda, que caracterizações simples que definem o tempo Presente em termos de experiência direta, e o tempo Passado em termos de memória, seriam viáveis se o uso da linguagem se limitasse a ocorrências físicas, mas como esse não é o caso, uma descrição que contemple casos mais gerais do Presente em inglês exige uma noção de imediaticidade epistêmica, um esquema mais elaborado que se baseia em modelos cognitivos e construções mentais. 
Dentro dessa perspectiva, os usos não presentes do Tempo Presente são exemplos de ocorrências virtuais que coincidem com o tempo de fala. Por exemplo, o caso do Futuro programado, que é expresso pelo verbo no Presente, evidencia que essas expressões se referem apenas indiretamente ao acontecimento; elas evocam uma espécie de programação virtual sobre a ocorrência esperada e consistem em representações mentais de eventos antecipados, como em $O$ avião chega à tarde, em que a frase descreve uma representação conceptual presente do evento real que se realizará no futuro.

A figura, a seguir, esboça uma programação que consiste de eventos virtuais, uma representação de acontecimentos reais antecipados. As linhas de correspondências (pontilhadas) indicam que o intervalo de tempo por meio do qual cada evento virtual é concebido como desdobramento é identificado com um tempo específico no Futuro. O cronograma é estável e mentalmente acessível por um período de tempo que inclui o Presente.

Figura 4 - Representação do futuro programado.

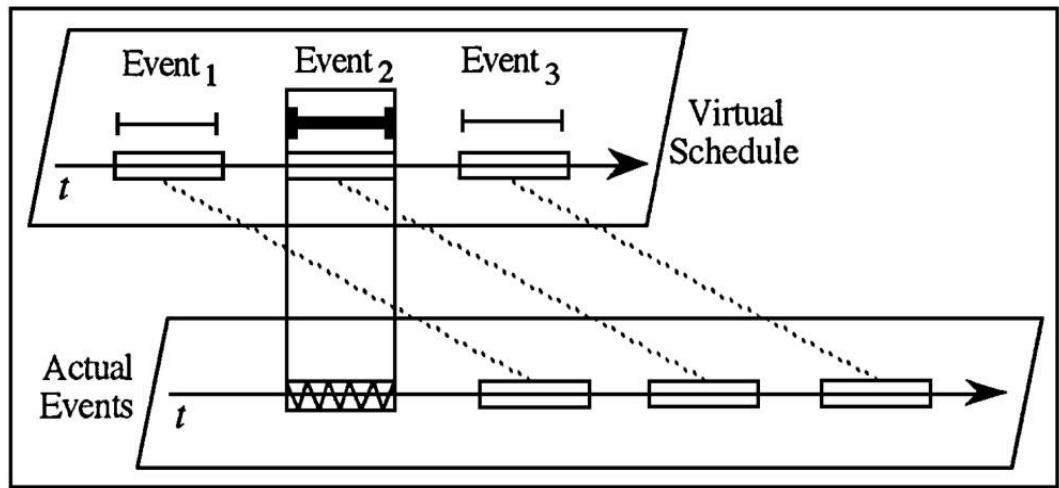

Fonte: Langacker (2001).

Dessa forma, o autor argumenta que o arranjo de visualização afeta o uso do tempo Presente, e que todos os casos que divergem do 
arranjo padrão invocam um tipo de construção mental, embora correspondam de alguma forma a eventos reais.

\section{Metodologia}

A pesquisa recorta, como objeto de estudo, o contraste entre Presente do Indicativo e tempos de Pretérito, simples e compostos, incluindo os Pretéritos Perfeito e Imperfeito e o Futuro do Pretérito , para indicação de eventos passados em manchetes e subtítulos jornalísticos. O objetivo é estabelecer as motivações conceptuais para cada tipo de uso, bem como verificar as combinações temporais observadas nesses recursos iniciais de acesso à notícia.

O recorte estabelecido tem duas motivações principais: a primeira é que embora o uso do Presente para indicar eventos passados se destaque em termos de frequência nas manchetes jornalísticas, esse fenômeno não mereceu ainda investigação adequada, em termos de suas motivações conceptuais; em segundo lugar, dada a primazia do uso do presente, resta explicar em que circunstâncias os tempos de pretérito são mantidos. A Tabela, a seguir, demonstra as frequências de uso dos tempos verbais mencionados:

Tabela 1 - Usos de tempos verbais em manchetes.

\begin{tabular}{|cc|cc|}
\hline \multicolumn{4}{|c|}{ Totais de ocorrência de manchetes no presente e no passado } \\
\hline Tempo Presente & $\%$ & Tempo Passado & $\%$ \\
\hline $85 / 115$ & $74 \%$ & $30 / 115$ & $26 \%$ \\
\hline
\end{tabular}


Com relação ao Banco de Dados, organizou-se um corpus composto de manchetes dos jornais online O Globo, Jornal do Brasil (JB), Estadão e Folha de São Paulo, selecionadas em destaque como primeira notícia das editorias. A escolha desses jornais foi motivada pela sua tradição no mercado e pela expressiva quantidade de usuários, que procuram este tipo de recurso para se informar com mais rapidez e facilidade sobre as notícias de sua cidade e do mundo.

A seleção foi realizada durante os cinco dias úteis da semana, entre os meses de março e abril de 2015. Observamos as escolhas temporais nas manchetes e subtítulos jornalísticos pelo Presente do Indicativo ou pelo Pretérito, para analisar as motivações que estão por trás dessas escolhas e acompanhar o desenvolvimento dos fatos. As hipóteses da pesquisa são as seguintes:

(i) As manchetes e subtítulos apresentam eventos cronologicamente passados, a partir de tempos verbais distintos.

(ii) Há alternância de tempos verbais entre manchete e subtítulo.

(iii) As escolhas temporais estão associadas ao tipo de ato de fala realizado.

As hipóteses descritas acima nortearam a análise dos dados, conforme detalhado na seção a seguir.

\section{Análise}


Nesta seção, serão apresentados os resultados referentes ao uso dos tempos verbais em manchetes e subtítulos.

Nas próximas subseções, desenvolvemos a interpretação dos dados levantados com base no corpus dos jornais online, os totais de ocorrência das manchetes e subtítulos no tempo Presente e no Pretérito e as combinações temporais entre manchetes e subtítulos, a fim de analisar e relacionar essas escolhas dos tempos verbais a aspectos cognitivos e pragmáticos.

\section{Tempos verbais em manchetes}

Com base em nosso corpus, apresentamos alguns exemplos de manchetes com os verbos no Presente do Indicativo:

(1) Diretora-gerente do FMI visita Alemão para conhecer programas sociais. (Jornal do Brasil).

(2) David Cameron propõe confiscar salários de imigrantes. (O Globo).

(3) Minas cria força-tarefa após morte de jornalista. (Estadão).

(4) PF realiza busca em apartamento da mulher do governador de Minas. (Folha de $\mathrm{SP})$.

Com base nos exemplos, observamos que as manchetes no Presente do Indicativo divulgam notícias, que embora relativamente recentes, enfocam eventos cronologicamente passados. Podemos considerar que esse é um uso especial do Presente e que necessita de um arranjo de visualização diferente do padrão, pois a escolha desse tempo verbal decorre de aspectos cognitivos, relacionados a 
construções mentais envolvendo representações de ocorrências, como será discutido na sub-seção final.

As manchetes que apresentam tempos verbais de Passado (Pretérito Perfeito, Pretérito Imperfeito e Futuro do Pretérito) podem ser assim ilustradas:

(5) Brasil teve 254 vítimas de tráfico de pessoas em 2013. (Jornal do Brasil)

(6) Quase meio milhão de brasileiros perdeu o emprego em 3 meses. (O Globo).

(7) FAB: Helicóptero com filho de Alckmin tinha problema. (Estadão).

(8) Del Nero aprovou contas de Marin, ex-presidente da CBF preso na Suíça. (Folha de São Paulo).

No caso das manchetes no Passado, percebemos que se trata do desenvolvimento de um fato que foi divulgado em outro momento, ou que faz parte do conhecimento de mundo socialmente compartilhado. No exemplo (5), a manchete apenas esclarece o número de vítimas, mas o fato de o tráfico de pessoas ocorrer no Brasil já é algo sabido pelo leitor; no exemplo (7), que divulga a causa do acidente com o filho do governador Alckmin, o acontecimento principal já foi noticiado, como podemos constatar na manchete anterior "Filho caçula de Alckmin morre em queda de helicóptero em SP” (Folha de São Paulo). A manchete, em (7), parece funcionar como uma forma reduzida de discurso direto. Assim, embora o verbo 'informar' não ocorra na manchete, o que se depreende é algo como "FAB informa: Helicóptero com filho de Alckmin tinha problema”, em que o foco principal é o ato de informar. 


\section{Tempos verbais em subtítulos}

O subtítulo é um elemento que reforça a intenção que consta nas manchetes, ou seja, a sua função é complementar, de ênfase às informações anunciadas pelas manchetes, que por sua vez devem chamar a atenção do leitor para a leitura da notícia. Abaixo, apresentamos exemplos de manchetes no Presente do Indicativo, acompanhadas de seus subtítulos:

Presente - Pretérito Perfeito

(9) Professores bloqueiam acesso a Viracopos por $\mathrm{th}$.

Segundo a PM, grupo de grevistas formou barreira na única ligação entre 2 rodovias e o aeroporto.

Presente - Pretérito Imperfeito

(10) Jornalista Sérgio Figueiredo morre no Rio de Janeiro.

Ele sofria de insuficiência cardíaca grave.

Presente - Futuro do Pretérito

(11) Câmara adia para dia 10 de junho votação da desoneração da folha.

Proposta original do governo reduziria a renúncia fiscal com a desoneração de $\mathrm{R} \$ 25$ bilhões para R\$12 bilhões ao ano. (Jornal do Brasil).

Presente - Presente

(12) Polícia usa bomba e agride jovem em protesto perto da USP.

Vídeo mostra agressão a manifestante em ato de alunos e servidores; um estudante foi preso. (Folha de São Paulo). 
No que se refere às manchetes no Passado, observemos os seguintes exemplos de subtítulos:

Passado - Pretérito Perfeito

(13) Dono de empreiteira confirmou 'comissões' em contrato do pré-sal.

Gerson de Mello Almada, da Engevix, disse que propina era extraída de acordos ainda em execução. (Estadão)

Passado - Pretérito Imperfeito

(14) Movimento 'No a la baja' definiu plebiscito feito no Uruguai sobre maioridade penal.

Em 2011, 65\% dos uruguaios defendiam a redução, mas a medida foi rejeitada em consulta pública. (O Globo)

Passado - Futuro do Pretérito

(15) Ricardo Teixeira e ex-presidente do Barcelona tinham sociedade.

Segundo a 'Época', a ligação dos dois dirigentes configuraria conflito de interesses. (O Globo)

Passado - Presente

(16) Caso Fifa: J. Hawilla cobrou US\$ 30 milhões da Nike.

'The Wall Street' revela mais um caso de propina. (Jornal do Brasil)

A partir dessa descrição inicial dos tempos verbais nos jornais, podemos pensar que a escolha mais acentuada do Presente nas manchetes reforça que a sua função essencial é a de "dar a notícia", atrair o interesse do leitor sem dar muitos detalhes; já os subtítulos apresentam uma variação maior entre Presente e Passado, por serem considerados elementos que descrevem os fatos, as circunstâncias, e 
revelam os atores envolvidos nos eventos, contribuindo para uma ampliação ou detalhamento dos principais aspectos da notícia.

Como no subtítulo já se tem conhecimento acerca do tema, o escopo temporal pode preceder o evento de fala para especificar informações relevantes que complementem as manchetes. Ainda assim, com manchetes no Presente, o Presente do Indicativo é mais frequente nos subtítulos do que o Passado:

Tabela 2 - Usos de tempos verbais em subtítulos.

\begin{tabular}{|cc|cc|}
\hline \multicolumn{4}{|c|}{ Totais de ocorrência de subtítulos no presente e no passado } \\
\hline Tempo Presente & $\%$ & Tempo Passado & $\%$ \\
\hline $60 / 115$ & $53 \%$ & $55 / 115$ & $47 \%$ \\
\hline
\end{tabular}

\section{Combinações temporais entre manchete e subtítulo}

A coleta de dados das manchetes e subtítulos evidenciou quatro grupos principais de combinações temporais entre esses dois elementos jornalísticos. No primeiro grupo, o tempo Presente é empregado na manchete e no subtítulo, como ilustramos nos exemplos abaixo:

1o Grupo: Presente - Presente

(17) Ex-gerente contesta sobrepreço em obras de refinaria.

Flávio Fernando Casa Nova fala à CPI da Petrobrás. (Jornal do Brasil).

(18) Incorporadora reduz exposição ao Minha Casa.

Com cortes no programa federal, empresa muda estratégia e foca na faixa dois do programa. (Estadão) 
Observamos que os subtítulos mantêm o foco no ato de fala de 'noticiar', a sua função é a de dar continuidade à apresentação da notícia, sem detalhar as causas e possíveis efeitos do evento. Como podemos notar na manchete (17) "Ex-gerente contesta sobrepreço em obras de refinaria", acompanhada do subtítulo "Flávio Fernando Casa Nova fala à CPI da Petrobrás", o destaque é a própria realização do ato de "dar a notícia". O subtítulo apenas especifica o agente e o local, mas a ação ainda evidencia a sua fala na CPI da Petrobrás, sem especificar os desdobramentos dos fatos anunciados. No exemplo (18), "Incorporadora reduz exposição ao Minha Casa”, com o subtítulo "Com cortes no programa federal, empresa muda estratégia e foca na faixa dois do programa", observamos que o enfoque no subtítulo permanece na divulgação da informação nova, da mudança de estratégia da empresa diante dos cortes no programa federal.

Este primeiro grupo de combinações temporais foi encontrado em $32 \%$ dos dados coletados, o que indica uma ocorrência bastante significativa de manutenção de foco no ato de fala.

O segundo grupo representa as manchetes no Presente, acompanhadas dos subtítulos no Passado. Essa combinação temporal corresponde à maior ocorrência nos jornais pesquisados. A porcentagem é de $42 \%$, o que indica que quase metade das manchetes muda seu foco do Presente para o Passado (Pretérito Perfeito, Imperfeito, Futuro do Pretérito), como podemos observar nos exemplos abaixo:

$2^{\circ}$ Grupo: Presente - Passado

(19) PF prende quadrilha que roubava cargas no interior de São Paulo. 
De acordo com a polícia, 24 pessoas foram presas em cinco cidades. Organização utilizava bloqueadores de sinais de rastreadores. (O Globo)

(20) EUA põem fim a programa de espionagem telefônica em massa. Sem acordo no Senado, autorização para a coleta de dados expirou nesta segunda-feira. (Folha de $\mathrm{SP})$

A alteração de tempo verbal da manchete para o subtítulo muda o foco do ato de fala para apresentar detalhes sobre os desdobramentos da notícia. Assim, no exemplo (19), é informada a quantidade de pessoas presas pela Polícia Federal e como a quadrilha atuava no roubo de cargas; (20) expõe o motivo da finalização do serviço de espionagem telefônica nos EUA: a ausência de um acordo no senado. Essa estratégia de alteração do tempo verbal sinaliza que a mudança de foco do Presente para o Passado ocorre quando o subtítulo aponta possíveis causas ou efeitos do evento anunciado.

O terceiro e quarto grupos apresentam manchetes no Passado, com o subtítulo mantendo o foco no pretérito, ou com alteração do tempo para o Presente.

$3^{\circ}$ Grupo: Passado - Passado

(21) IBGE: renda do trabalhador caiu $5 \%$ além da inflação em doze meses. Rendimento em seis metropolitanas registrou em maio o quarto recuo seguido. (O Globo)

(22) Briga entre poderosos dirigentes teria iniciado investigação da Fifa.

Jack Warner, da Concacaf, teria cometido "traição" ao apoiar escolha do Catar como sede da Copa do Mundo. (Jornal do Brasil)

$4^{\circ}$ Grupo: Passado - Presente 
(23) FAB: Helicóptero com filho de Alckmin tinha problema.

Relatório mostra que danos causados nas pás e nos motores foram consequência, não causa do acidente. (Estadão)

(24) Propina para sediar Copa envolveria África do Sul.

Carta revela que dois ministros do governo foram consultados sobre pagamentos. (Estadão)

O exemplo (21) apresenta a manchete e o subtítulo no Passado que divulgam assuntos já de conhecimento do leitor. É de domínio público que o IBGE tem atribuições relacionadas a estatísticas sociais, demográficas e econômicas, e organiza informações sobre os censos realizados no País; por isso, já se espera algum dado estatístico de pesquisa do instituto. A manchete apresenta o resultado de uma investigação sobre a queda da renda do trabalhador em doze meses, e o subtítulo especifica o registro do rendimento em seis regiões metropolitanas no mês de maio.

No caso do exemplo (22), podemos observar a informação de que já estava em curso a investigação sobre a Fifa, mas a relevância agora são as causas que teriam dado início à apuração do caso: a briga entre os dirigentes que é detalhada no subtítulo, a traição de um membro da Concacaf e seu apoio para a escolha do Catar como sede do evento. A notícia principal já foi divulgada em jornais anteriores, "Investigação na Fifa: Marin é acusado de receber ao menos R\$ 20 milhões em propina” (Jornal O Globo). A escolha expressa as possíveis causas/efeitos, visto que não se trata mais do ato de fala de noticiar a investigação. É interessante notar, também, que o Futuro do Pretérito Composto 
parece ser utilizado em textos jornalísticos para sinalizar que o redator evita se comprometer com os fatos relatados.

No último grupo, as manchetes estão no Passado, mas há alteração do tempo verbal para o Presente no subtítulo. Como já comentamos acima, o exemplo (23) revela o que poderia ser uma das causas do acidente com o filho do governador Alckmin, mas o interessante é que o subtítulo apresenta um novo elemento ao caso, o relatório. Para indicar uma mudança nas investigações, a informação de que os danos nas pás e motores do helicóptero seriam a consequência do acidente e não o motivo, o tempo escolhido é o Presente do Indicativo.

O mesmo ocorre em (24). Já se sabe que houve o pagamento de propina para sediar a Copa, mas o subtítulo divulga a revelação de que dois ministros do governo estariam envolvidos nesses pagamentos. Essa última alteração de tempo verbal sugere que o foco volta a ser o ato de "dar a notícia"; o fato já é de conhecimento público, mas há novos elementos que surgem e são noticiados no Presente.

A Tabela 3 apresenta os resultados para as diferentes combinações temporais entre manchetes e subtítulos:

Tabela 3 - Grupos de combinações temporais.

\begin{tabular}{|cc|cc|cc|cc|}
\hline \multicolumn{8}{|c|}{ Combinações temporais entre manchetes e subtítulos } \\
\hline \multicolumn{2}{|c|}{ Presente-Presente } & \multicolumn{2}{|c|}{ Presente-Passado } & \multicolumn{2}{|c|}{ Passado-Passado } & \multicolumn{2}{c|}{ Passado-Presente } \\
\hline $36 / 115$ & $32 \%$ & $48 / 115$ & $42 \%$ & $7 / 115$ & $5 \%$ & $24 / 115$ & $21 \%$ \\
\hline
\end{tabular}

A Tabela 3, referente às combinações temporais revela que os grupos Presente-Passado e Presente-Presente são os mais significativos. Contudo, o uso do Tempo Presente nas manchetes e do Tempo Passado 
nos subtítulos ainda representa o grupo mais frequente, com $42 \%$ dos casos.

Como observamos na análise, os subtítulos mantêm o uso do Presente do Indicativo quando mantêm o foco no ato de fala de 'dar a notícia', mas mudam para o Passado (Pretérito Perfeito, Imperfeito, Futuro do Pretérito) quando apontam possíveis causas ou efeitos do evento anunciado.

Após o ato de 'dar a notícia' na manchete, a referência a causas e/ou efeitos do evento reportado, no subtítulo, constitui uma estratégia cognitiva de focalização, que visa atrair a atenção do leitor para a matéria a ser lida. Isso explica a tendência de alteração do tempo verbal da manchete para o subtítulo, conforme indicado a seguir:

Tabela 4 - Variação do tempo verbal da manchete para o subtítulo.

\begin{tabular}{|c|c|}
\hline Manutenção de tempo verbal & Alteração de tempo verbal \\
\hline $43 / 115$ & $72 / 115$ \\
\hline
\end{tabular}

A Tabela 4 evidencia que a alteração do tempo verbal da manchete para o subtítulo ocorre em $63 \%$ dos dados coletados, em oposição à manutenção de tempo verbal que representa 37\% dos casos.

\section{Discussão}

Como apontado no decorrer do trabalho, o Presente do Indicativo é normalmente utilizado para retratar eventos concomitantes ao momento em que falamos, mas também admite usos que se afastam desse padrão, voltados para fazer previsões sobre o futuro, indicar ações 
habituais, ou ainda para atribuir mais vivacidade e dinâmica aos fatos passados. No caso do objeto de estudo desta pesquisa, a partir da proposta de Langacker (2001, 2009) para esses usos que se afastam do padrão, argumentamos que a escolha predominante do Presente do Indicativo em manchetes jornalísticas sinaliza, ao mesmo tempo, a realização de um ato de fala no escopo imediato e a referência a um evento anterior ao evento de fala.

Os resultados preliminares encontrados com base em nossa análise evidenciam que:

1) As manchetes ocorrem, predominantemente, no Presente do Indicativo, embora se refiram a eventos cronologicamente passados.

2) Os subtítulos se distribuem, de forma mais ou menos equilibrada, entre os tempos Presente (53\%) e Passado (47\%).

3) A combinação mais frequente é manchete no Presente e o subtítulo no Passado, evidenciando uma tendência de alteração de tempo verbal da manchete para o subtítulo.

$\mathrm{O}$ uso do Presente do Indicativo em manchetes reflete um processo cognitivo associado ao ato pragmático de "noticiar", em que o tempo verbal não faz referência ao evento em si, mas à realização de um ato de fala ('dar a notícia'), concomitante ao Ground (o evento discursivo e seus participantes). Por não fazer referência direta ao evento, entendemos que esse Presente empregado nas manchetes indica que o conteúdo conceptual é interpretado como uma ocorrência 
virtual. Como vimos, Langacker define que o Tempo Presente em inglês especifica que uma instância do processo perfilado ocorre e coincide precisamente com o momento da fala ou, mais frequentemente, que um processo epistêmico associado ao evento é concomitante ao momento da fala. Nosso estudo permite ampliar essa última proposta, apontando a possibilidade de um processo cognitivo de natureza pragmática. Assim, entendemos que o uso do Presente nas manchetes e subtítulos corresponde ao ato de fala de "noticiar", que é concomitante ao evento discursivo.

$\mathrm{Na}$ figura abaixo, adaptamos o modelo langackeriano ao nosso objeto de estudo:

Figura 5 - Presente das manchetes de jornais online.

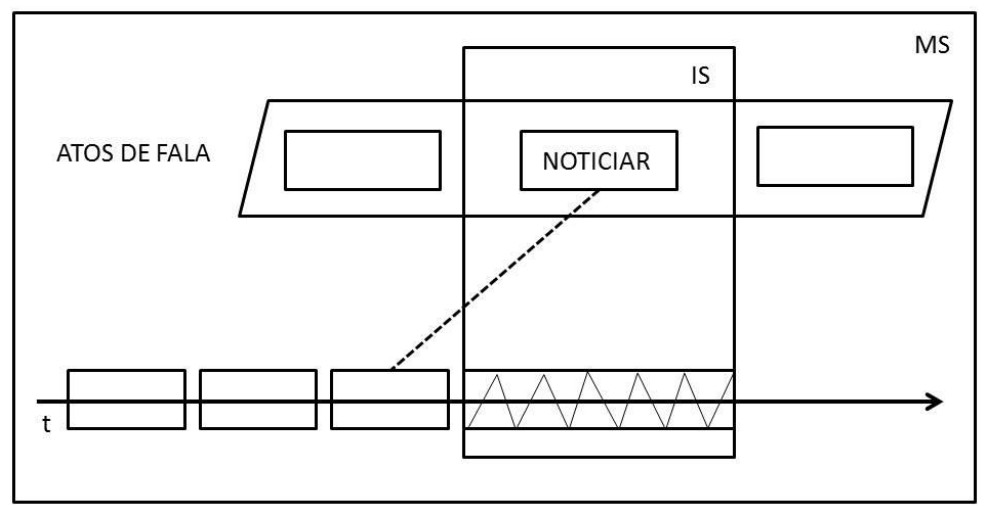

Fonte: Adaptado de Langacker (2001).

A diferença do que ocorre nas manchetes para o que se verifica no Futuro programado, por exemplo, é que os eventos atuais não seriam antecipados; ao contrário, como os eventos reais já ocorreram, eles se posicionam antes da ocorrência virtual, de modo que as linhas pontilhadas os associam à realização do ato de fala de 'noticiar', sinalizado por meio do tempo Presente. 
Langacker conclui que o problema de conceituação do Presente como coincidente com o tempo de fala e o seu uso em situações no passado, futuro ou atemporais devem ser analisadas por uma semântica que considere essas questões subjetivas e fictícias que ultrapassam a mera descrição do tempo com base na relação entre o tempo da fala e a duração da ocorrência de um evento real. Este trabalho se alinha a essa proposta, trazendo mais uma evidência para uma perspectiva que considere a semântica cognitiva para analisar as manchetes de jornais e seus aspectos pragmáticos que fogem à visão objetivista da linguagem.

Essas reflexões são essenciais para compreendermos as escolhas temporais nas manchetes dos jornais online, já que seu emprego não corresponde à noção prototípica do Presente, definida por uma análise formal ou apenas semântica. Já percebemos, portanto, que outros elementos relacionados à situação de comunicação também devem entrar em jogo.

Como vimos na análise, o tempo Presente não indica imediatismo do evento em relação ao momento da fala, mas uma imediaticidade pragmática. O fato de o evento ter ocorrido indicaria o emprego do pretérito associado à noção de certeza epistêmica, mas no caso das manchetes é o Presente do Indicativo que estabelece esse significado. Essa constatação corrobora a hipótese de que o sentido do tempo aqui não está relacionado a nenhum tipo de localização cronológica, mas a um ato pragmático de noticiar os acontecimentos. Por essa razão, não faz sentido verificar se o evento real coincide ou não com o tempo de fala; estamos lidando com a experiência mental, o modo como acessamos os acontecimentos. Nestes termos, a noção de coincidência 
temporal é analisada a partir de aspectos cognitivos e pragmáticos, corroborando a afirmação de Langacker de que é possível e coerente definir o tempo Presente como coincidente com o tempo de fala, em razão de sua perspectiva ir além da experiência direta da ocorrência perfilada pelo falante.

Retomando a definição de Langacker para o Tempo Presente como processo perfilado que ocorre e coincide com o momento da fala, é necessário enfatizar que o significado aqui é equiparado à conceptualização; a expressão linguística sinaliza a maneira como interpretamos o conteúdo conceptual. Muitos eventos virtuais representativos são mentalmente reconstruídos a partir de suas descrições no Presente. É o que ocorre com os usos não presentes do tempo Presente, como o Futuro programado, em que não há referência direta ao evento futuro planejado, mas a consulta ao cronograma ativa o evento de representação perfilado; um script como uma programação, em que os eventos representativos virtuais são mentalmente reconstruídos a partir de suas descrições; e o caso do genérico singular, uma entidade virtual que representa o que é comum a qualquer número de ocorrências reais; essa ocorrência virtual coincide com o momento da fala.

Os dados discutidos na análise procuraram evidenciar as hipóteses apresentadas na Metodologia. Os resultados demonstram que (i) as manchetes e subtítulos apresentam eventos cronologicamente passados, a partir de tempos verbais distintos; (ii) há alternância de tempos verbais entre manchete e subtítulo; (iii) a escolha do Presente do Indicativo está associada a tipo de ato de fala realizado pela notícia. 


\section{Considerações finais}

Este trabalho investigou escolhas temporais/aspectuais em manchetes e subtítulos jornalísticos, enfocando o uso do Presente do Indicativo e de tempos de Pretérito para indicar eventos passados. A análise e discussão dos dados evidenciou que a configuração das manchetes dos jornais online sinaliza um envolvimento do sujeito no arranjo da notícia. Ao empregar o Tempo Presente para noticiar os acontecimentos passados, há uma configuração do discurso voltada para a relação de interatividade com o leitor, o que de certa forma baliza a expressão do conceptualizador.

Argumentamos que o Presente do Indicativo em manchetes e subtítulos sinaliza a realização do ato de fala de noticiar, concomitantemente ao evento de fala. Em termos quantitativos, os resultados apontaram, ainda, para a escolha temporal predominante do Presente, embora o emprego do pretérito em subtítulos tenha se mostrado bastante expressivo. Além disso, verificamos a tendência de alteração do tempo verbal da manchete para o subtítulo. O foco muda do ato de fala para a referência a causas e/ou efeitos do evento reportado, relacionada à estratégia cognitiva de focalização.

Por fim, vale destacar que a proposta aqui apresentada permitiu o refinamento descritivo da caracterização do Presente do Indicativo em português, ao enfocar um contexto que ainda não havia merecido análise detalhada na literatura, como também ampliou horizontes explicativos ao tratar do fenômeno em termos de conceptualização. Ao 
integrar aspectos linguísticos e cognitivos na análise de produtos socioculturais relevantes, como manchetes e subtítulos jornalísticos, acreditamos ter conjugado as sementes plantadas por Marcuschi, no panorama linguístico brasileiro, aos desenvolvimentos mais recentes da Linguística Cognitiva.

\section{Referências}

FERRARI, Lilian. Introdução à Linguística Cognitiva. São Paulo: Contexto, 2011. BAKHTIN, M. Estética da criação verbal. 4. ed. Trad. P. Bezerra. São Paulo: Martins Fontes, [1979]; 2003.

CASTILHO, A. T. Nova gramática do português brasileiro. São Paulo: Contexto, 2010 .

CUNHA, C.; CINTRA, L. Nova gramática do português contemporâneo. 3. ed. Rio de Janeiro: Nova Fronteira, 2001.

DECAT, M. B. N. A relevância da investigação dos processos linguísticos, numa abordagem funcionalista, para os estudos sobre os gêneros textuais. In: ANTONIO, J. D. (Org.). Estudos descritivos do português - história, uso, variação. São Carlos: Claraluz, 2008, p. 169-191.

ESTADÃO. Disponível em: < http://www.estadao.com.br/>. Acesso em: março-abril de 2015 .

FAUCONNIER, G.; SWEETSER, E. (Eds.). Spaces, Worlds, and Grammar. Chicago and London, The University of Chicago Press, 1996.

FOLHA DE SÃO PAULO. Disponível em: <www.folha.uol.com.br/>. Acesso em: março-abril de 2015 .

JORNAL DO BRASIL. Disponível em: <www.jb.com.br>. Acesso em: março-abril de 2015 .

LAKOFF, G.; JOHNSON, M. Philosophy in the flesh: the embodied mind and its challenge to western thought. New York: Basic Books, 1999. 
LANGACKER, R. Foundations of cognitive grammar. vol. I: Theoretical prerequisites. Standford CA: Stanford University Press, 1987.

Foundations of cognitive grammar. vol. II: Descriptive applications. Standford CA: Stanford University Press, 1991.

. The English Present Tense. English Language and Linguistics 5.2: 251-272.

Cambridge University Press, 2001.

. The English present: Temporal coincidence vs. epistemic immediacy. In: Investigations in cognitive grammar. Mouton de Gruyter Berlin, New York, 2009. (Cognitive linguistics research; 42).

MARCUSCHI, Luiz Antônio. Aspectos linguísticos, sociais e cognitivos na produção de sentidos. Revista do Gelne, a. 1, n. 1, 1999.

A. Da fala para a escrita: atividade de retextualização. São Paulo: Cortez, 2000.

Produção textual, análise dos gêneros e compreensão. São Paulo: Parábola, 2008.

O GLOBO. Disponível em: <http://oglobo.globo.com/>. Acesso em: março-abril de 2015 .

PERINI, M. Gramática Descritiva do Português. 4. ed. São Paulo: Ática., 2009. . Gramática do português brasileiro. São Paulo: Parábola Editorial, 2010.

SAID ALI, M. Gramática secundária da língua portuguesa. 3. ed. Brasília: Ed. Universidade de Brasília, 1964.

Gramática histórica da língua portuguesa. 3. ed. Brasília: Ed. Universidade de Brasília, 1964.

SOARES, Caroline. O tempo presente em manchetes online: o uso do presente do indicativo para referência ao passado recente. Dissertação (Mestrado em Letras). Instituto de Letras. Universidade Federal Fluminense, Niterói: 2013.

Recebido em 28/11/2017.

Aprovado em 22/12/2017. 